\title{
Study on Research-Oriented Teaching Based on Project Guidance in Signal Processing Courses
}

\author{
Zhang Feng \\ Xi an Technological University \\ Xi'an, China \\ zf_zx963@163.com \\ Dou Yuqin \\ Xi`an Technological University \\ Xi'an, China \\ 925879353@qq.com
}

\author{
$\mathrm{Xu}$ Yinxi \\ Xi an Technological University \\ Xi'an, China \\ 1075818920@qq.com \\ Zhao Li \\ Xi`an Technological University \\ Xi'an, China \\ pilly_lily@126.com
}

\begin{abstract}
The signal processing courses are theoretically strong and mathematically advanced. At same time, they also provide basic theories and basic methods for the construction and design of information processing systems. Traditional teaching method centered on teachers focuses on theoretical teaching, and lacks training on the relationship between the theory mastered by students and the ability to solve practical problems in information processing. The paper introduces research-oriented teaching into the signal processing courses to solve the above problems. By means of the combination of project-guided task-driven teaching, a student-centered and research-oriented teaching model is established to cultivate students' engineering application ability and innovation consciousness. Based on G3-PLC physical layer signal processing project, the practice of research-oriented teaching in digital signal processing is carried out. The research-oriented teaching is carried out in terms of project analysis, task design, task decomposition, task implementation and effect evaluation. Theoretical analysis and teaching practice show that the research-oriented teaching is necessary, the reform of teaching methods based on project guidance is an effective way to construct research-oriented teaching of signal processing courses and task driven is an effective supplement to project guidance teaching.
\end{abstract}

Keywords-Research-Oriented Teaching; Signal Processing Courses; Project Guidance; Task Driven; G3-PLC

\section{INTRODUCTION}

Signal processing courses usually include signals and system, digital signal processing, digital image processing, information theory and coding. They are the professional foundation and professional courses for electronic information engineering and related majors. Traditional teacher -centered teaching methods is lack of practical engineering project background and pertinence, and has limited effect on the training of application ability and inquiry learning ability. This is not compatible with the training objectives of applied talents and the requirements of professional accreditation for engineering education. In order to solve these problem, this paper studies how to establish research-oriented teaching based on the combination of project- guidance and task-driven teaching in signal processing courses and carries out teaching practice through the G3-PLC physical layer signal processing project.

\section{Characteristics of Signal Processing Courses}

Signal processing courses are major basic or major courses in electronic information engineering, electronic information science and technology, and communication engineering. In practical teaching, the common characteristics of these courses are as follows:

- There are many mathematical methods and mathematical derivations in these courses, which have strong theoretical nature.

- The core content of these courses is the theoretical basis of many information processing systems and data acquisition and analysis systems, which provide the necessary means of information processing for these systems. Therefore, these courses have strong engineering applicability ${ }^{[1-3]}$.

At present, most of these courses are based on teacher centered traditional teaching methods. This way of teaching emphasizes theoretical analysis and deduction, and there is a lack of the students' ability to solve practical engineering problems with the relevant principles and algorithms of signal processing. Even if the content of algorithm simulation and algorithm application is added to the content of the course, there is a lack of practical engineering project background and lack of pertinence, and it has limited effect on the training of application ability and inquiry learning ability. This is not compatible with the training objectives of applied talents and the requirements of professional accreditation for engineering education. 


\section{NECESSITY OF RESEARCH-ORIENTED TEACHING IN SignAL PROCESSING COURSES}

Research-oriented teaching is a new method generally advocated at home and abroad in recent years, which regards students as the center of curriculum teaching. This teaching method guides students to research and cognition to realize knowledge discovery and re discovery, and form research quality and innovation ability in this process. At the same time, this teaching method emphasizes the guidance of teachers, students' participation in classroom and independent inquiry in the course of teaching, so it also plays an active role in stimulating students' interest and cultivating the ability to explore and research ${ }^{[5]}$.

At present, the professional accreditation of engineering education has been implemented in many countries. It is an important foundation for mutual recognition of engineering education and international recognition of engineer qualifications. In China, the professional certification of engineering education has also received extensive attention. The development of relevant certification work has a positive significance to promote the international mutual recognition of China's engineering education and enhance the international competitiveness of the engineering and technical personnel. The core concept of engineering education professional certification is Outcome based education (OBE), which emphasizes the main position of students in the course teaching, and pays more attention to the innovation and practicality of knowledge in the course of teaching. OBE requires students to demonstrate their abilities through challenging tasks, such as project proposals, project planning, case studies, and oral reports. OBE pays more attention to creative thinking, analysis and synthesis of information, planning and organization ${ }^{[7-9]}$.

Under the background of engineering education professional certification, the traditional teacher- centered teaching method is difficult to meet the basic requirements of the OBE concept. On the basis of various advanced teaching methods, the transformation of curriculum teaching to research teaching mode is the basic requirement of professional certification, and it is also the necessary means for the implementation of the OBE teaching concept in the actual teaching process.

\section{CONSTRUCtion OF RESEARCH-ORIENTED TEACHING BASED} ON PROJECT GUIDANCE

\section{A. Project Guidance and Task Driven}

The project-guided teaching method is based on the cognitive learning theory, and it is a change to the traditional teaching mode of 'first theory and post practice'. This method regards the solution of practical problems as the purpose of teaching. And in the process of teaching, the students can achieve knowledge acquisition and ability training by solving practical problems. In Signal processing courses, organizing and conducting curriculum teaching with project guidance can cultivate students' engineering consciousness. At the same time, by integrating curriculum theory with practical engineering projects and practical applications, their understanding of theoretical knowledge can be strengthened and their interest in learning can be stimulated. So, project-guided teaching is an effective teaching method for the establishment of research teaching mode in signal processing courses.

Task driven is an interactive teaching method based on constructivist teaching theory. This teaching method takes the completion of the tasks as the clue, and imply the teaching content in a series of carefully designed tasks, so that the students can find out the problem through the analysis and implementation of the task and find the way to solve the problem. Through this way, we can cultivate students' innovative consciousness, innovative ability, engineering application consciousness and autonomous learning habits. In the construction of research-oriented teaching mode, task driven can form effective supplement to project guidance teaching, and strengthen students' main position in the teaching process ${ }^{[10-11]}$.

\section{B. Establishing Research-Oriented Teaching Through Project Guidance}

We can take the teaching method 'project guidance as the basis, task driven to supplement' as a means to realize the transformation of the research teaching mode of the signal processing courses. The combined application of task driving and project guidance is to form a multi task driven teaching mode under the guidance of the project. This method integrates the project guided teaching with the task driven teaching effectively, takes the project as the carrier, transforms the project target into a series of relative independent tasks, and takes the implementation of the specific task as the basic means to realize the project goals. Therefore, it can better play the role of project guidance and task driving in practical teaching application. The introduction of multiple tasks can turn the whole project goal to zero and make the task more enforceable. Appropriate expansion and careful design of multiple tasks will cover the theoretical knowledge of the curriculum more comprehensively and avoid the shortage of single task. At the same time, multiple tasks facilitate the implementation of group implementation in the teaching process, and foster the ability of teamwork to solve practical problems.

\section{RESEARCH-ORIENTED TEACHING PRACTICE UNDER PROJECT GUIDANCE}

\section{A. Research-Oriented Teaching in Signal Processing Courses}

The section 2, we mentioned that signal processing courses are highly practical and applicable. In view of this characteristic, we can introduce the multi-task driven teaching method under the guidance of the project to the relevant curriculum teaching. Through the actual project and the reasonable design of the course tasks, we can fully arouse the students' interest in learning, promote the relationship between the theoretical content and the engineering application, cultivate the students' ability to apply the principle of signal processing to solve the practical engineering problems, so as to improve the teaching quality and realize the research-oriented teaching mode. Under the guidance of practical engineering projects, we have carried out the research-oriented teaching in the course 'digital signal processing'. 


\section{B. Selection of Project and Design of tasks}

The selection of case projects and the rational design of tasks are the basis for the implementation of the above teaching methods, and two factors need to be taken into full consideration:

(1) The case project should come from the actual engineering project, and the key technology of its implementation should be the core content of the course.
(2) The designed tasks involve one or more core knowledge points in the course, and can solve a relatively complete core technical problem in the project.

We chose the actual research project 'G3-PLC physical layer signal processing' as the case project for the implementation of research-oriented teaching in digital signal processing course.

G3 is an international standard for power line carrier communication, and the physical layer is the basic layer of G3PLC. The physical layer is based on the OFDM modulation technology, and the signal transmission model is as follows:

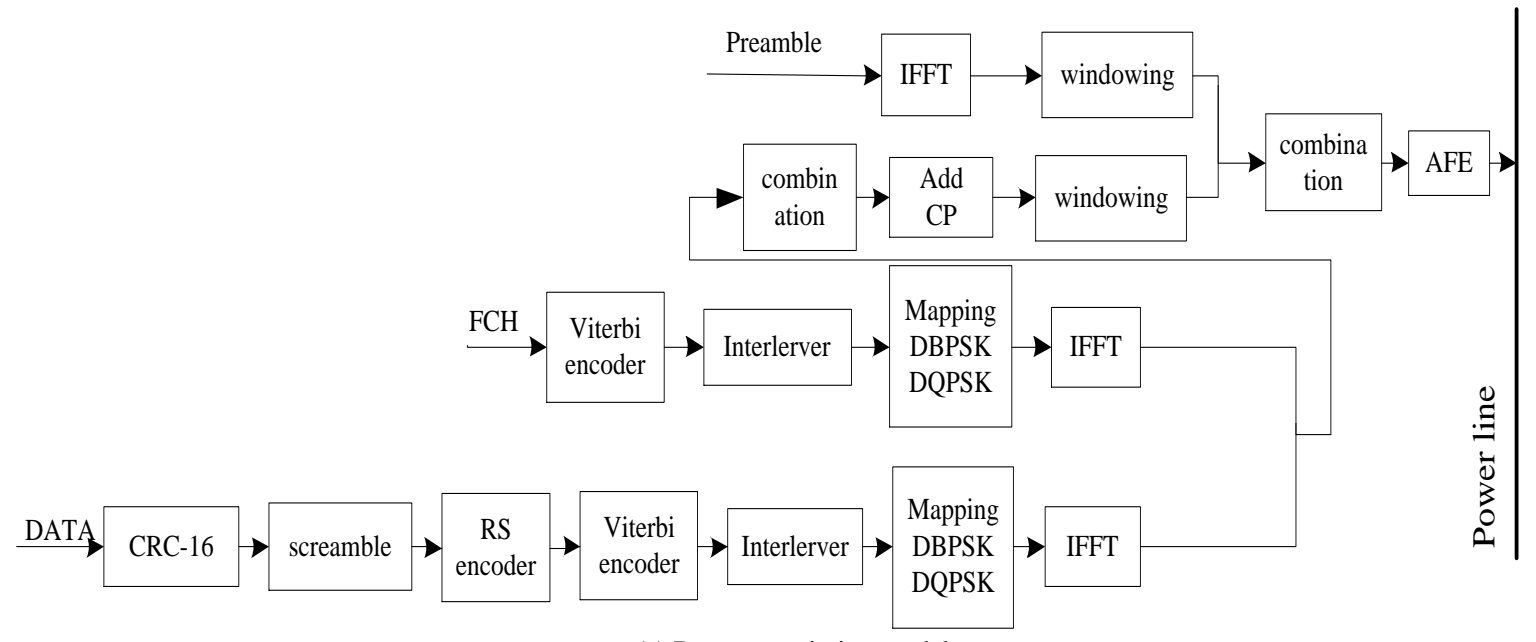

(a) Data transmission model

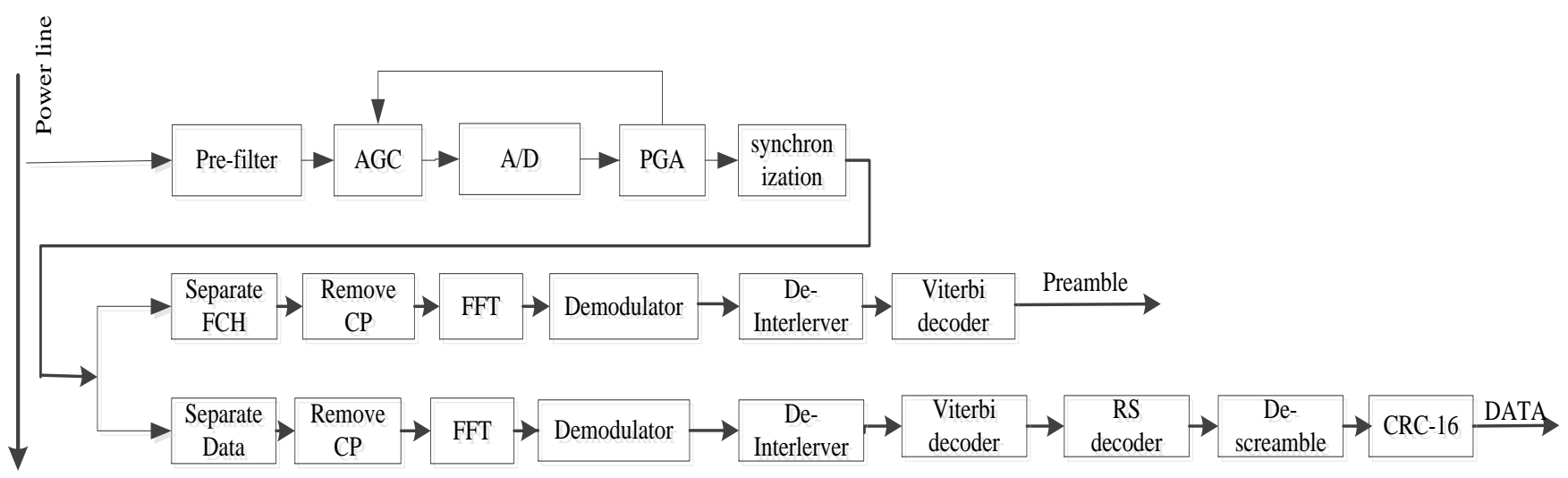

(b) Data receiving model

Fig. 1 Physical layer signal transmission model in G3-PLC

Figure 1 (a) is the data transmission model. The data to be transmitted is scrambled and then encoded by Reed-Solomon and convolution codes. Reed - Solomon coding and convolution coding have the function of forward error correction. The encoded data are interleaved to make the bit error random, which is convenient for error correction. After interleaving, the data is modulated by DBPSK or DQPSK, and then IFFT transform. Thus, the original OFDM signal is formed. In order to eliminate inter symbol interference and inter channel interference, cyclic prefix and windowing are needed for OFDM signal. Finally, the signal is amplified and coupled to the power line. Figure 1 (b) is the data receiving model, which is almost the inverse operation of the transmission model. The signal received by the power line is pre-filtered and amplified automatically, and then demodulated, and finally the physical layer signal is reduced to the original data. The RS coding introduced in the model has a significant effect on correcting random errors and suppressing burst noise interference.

According to the project functional requirements, technical indicators and the teaching objectives of digital signal 
processing, the core content of the project is decomposed to form three tasks, which are as follows:

- Generation of the OFDM signal in the physical layer. This task is based on IFFT to realize the generation of physical layer's OFDM signals in G3-PLC, corresponding to the contents of 'Discrete Fourier transform and its fast algorithm' in the course.

- Generation of the OFDM signal in the physical layer. This task is based on IFFT to realize the generation of physical layer's OFDM signals in G3-PLC, corresponding to the contents of 'Discrete Fourier transform and its fast algorithm' in the course. analysis of the signal filtering algorithm on the basis of the spectrum analysis of the G3-PLC physical layer signal, corresponding to the content of the 'digital filter design' in the course.

\section{Implementation of Research-Oriented Teaching Under Project Guidance}

According to the relevant theory of the task driven teaching method and the practical characteristics of the course, the implementation of the task driven teaching method is shown in Figure 3.

- The filter processing of the OFDM signal. This task completes the design, simulation and performance

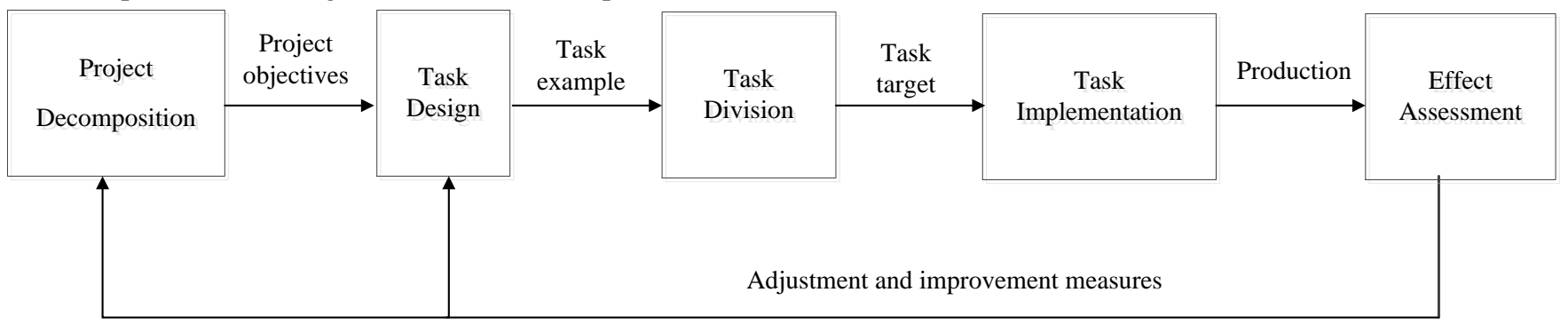

Fig. 2 The implementation of research-oriented teaching

This implication plan takes students as the center, emphasis on the ability cultivation of finding and solving problems. In the course teaching, the teacher is mainly responsible to design for the task, and to guide students during the task implementation process. In the implementation plan, the good mission design is basis of task driven teaching, which designed by teachers according to the project. Task division is carried out according to the course content and knowledge module. Task implementation takes the student as the center to carry on, and the teacher provide the necessary instruction. Effect evaluation carries out, combined with task completion process, production and actual project technical indicators, evaluation results on the one hand, as an indicator of curriculum assessment, on the other hand, as a basis for the task adjustment and perfection. Specific course teaching practice proves that multitask driven teaching under the guidance of the project can mobilize the enthusiasm of students learning, learning interest and class participation, completing the design plan and specific task implementation under the driven by the project's lead and mission requirements, submitting the production so as to achieve the purpose of training research ability .Meanwhile, the introduction of feedback mechanism in the implementation process ensures the teaching effect, quality of task design and the effective implementation of this teaching method.

\section{Selection of Project and Design of tasks}

The research-oriented teaching method, which is based on multi-task driven guided by real project has been applied in the actual teaching of digital signal processing and obtained the good teaching effect. The introduction of engineering projects promotes the link between curriculum theory and engineering practice. The multiple curriculum tasks designed reasonably stimulate the students' interest in learning, and exercise their ability to solve practical problems by using the theory and algorithms of digital signal processing. The overall teaching effect of the course has been greatly improved. The researchoriented teaching method has promoted the transformation of the teaching mode of the course to the student- centered inquiry teaching, and has a certain positive role in realization of the cultivating practical talents and research talents.

\section{CONCLUSIONS}

Theoretical analysis and teaching practice in this paper show that:

- The research-oriented teaching mode is very necessary for the transformation of the teaching mode of the signal processing courses to the student- centered inquiry teaching, and the improvement of the students' ability of applying the basic theory of signal processing to solve practical engineering problems.

- The reform of teaching methods based on project guidance is an effective way to construct the researchoriented teaching mode of signal processing courses. 
- Task driven teaching method is an effective supplement to project guidance teaching method and an effective means to stimulate students' inquiry learning motivation.

\section{ACKNOWLEDGMENT}

Fund Project: Research project of postgraduate education reform of Xi'an Technology University.Title:results-oriented, graduate student-centered reform of modern digital signal processing.

Number:XAGDYJ180210

\section{REFERENCES}

[1] LI Xiukun, LOU Jiu,ZHANG Yan. Research and implementation of "adaptive", task-driven experimental teaching mode[J]. Experimental Technology and Management, 2015, 32(5):24-27. (In Chinese)

[2] TAN Liyuan, ZHANG Suodi, JIN Shuwei. Research on the TaskDriving Teaching Mode of Applied GIS Course[J]. Journal of Higher Education Finance, 2018(1). (In Chinese)

[3] Liao M C, Li J. Goal-Oriented Method and Practice in Experimental Teaching[J]. Ieri Procedia, 2012, 2(4):480-484.

[4] ZHAO Yue, RU Tingting. Construction and Research of Task-Driven Instruction Model Based on Computational Thinking[J]. Journal of Jilin Radio and TV University, 2017(2):10-11. (In Chinese)

[5] LI Jie. The exploring and practicing of the reading teaching Under the target-lead teaching theories [D]. Guangxi Normal University, 2007. (In Chinese)

[6] SMIDA B. Coding to Reduce the Interference to Carrier Ratio of OFDM Signals [J]. Eurasip Journal on Wireless Communications and Networking, 2017(1):21.

[7] WANG Yingmi, ZHANG Leping. Analysis of Case Teaching Database for Full-time Master of Engineering[J]. Higher Engineering Education Research, 2013(4):166-171. (In Chinese)

[8] LI Hanmei. Observation and Enlightenment of Case Teaching in Classroom Teaching of Teacher Education[J]. Teaching in Chinese universities, 2013(6):72-74. (In Chinese)

[9] ZHANG Bing. Simulation and Design of OFDM Communication System Based on MATLAB[J]. Wireless Internet Technology, 2016(11):4. (In Chinese)

[10] LI Lan. Analysis of Case Teaching Method[J]. Journal of Yunnan University of Finance and Economics, 2004(s1):347-349. (In Chinese)

[11] Liqiao, Geng. The Practice Research of Task Driving Method in Basic Teaching of Information Technology[J]. International Journal of Technology Management, 2013:51-53.

[12] Yang C. Studies on the Task-driven Model in the Teaching of Basic Course of Computer Science[J]. Journal of Henan Radio \& TV University, 2008. 